\title{
Resistance Properties of Al-Si Coatings
}

\author{
B. KuCHARSKA* AND J. KOWALCZYK \\ Institute of Materials Engineering, Faculty of Production Engineering and Materials Technology, \\ Technical University of Częstochowa, Częstochowa, Poland
}

\begin{abstract}
Modern methods for modification of properties and protection of material surface, which embrace gaseous phase physical deposition methods, arouse interest of many branches of industry as well as medicine. By virtue of their fine-grained structure, metallic coatings fabricated by these methods have superior mechanical properties and corrosion resistance when compared with alloys made by traditional techniques. The paper presents a study of the electrical properties and structure of Al-Si coatings. The coatings were deposited by physical vapor deposition. Targets of hypo-, peri- and hypereutectic composition alloys were sputtered using the magnetron process. The coatings were the resistance element in the dc current circuit and measurements were carried out by the fourpoint method. Based on current-voltage parameters, the coatings electrical resistance was determined at specified temperatures. It was found that an increase of $\mathrm{Si}$ content in the chemical composition of the coatings resulted in an increase of their resistance and the maximum temperature to which the coating heats up. By means of a X-ray diffraction the occurrence of thin film of aluminum and silicon oxides on the coatings surface were detected. The oxide film increases resistance of the coatings and hamper measurements at low voltage.
\end{abstract}

DOI: 10.12693/APhysPolA.129.197

PACS: 73.61.At, 81.07.Bc, 81.15.Cd

\section{Introduction}

Aluminum is the fourth best electrical conductor among metals, next to silver, copper and gold.

The electrical conductivity of aluminum, which is $1.72 \times 10^{-8} \Omega \mathrm{m}\left(\right.$ at $20^{\circ} \mathrm{C}$ ), is equivalent to only approximately $60 \%$ of the copper conductivity, yet $\mathrm{Al}$ application is quite wide in electrical equipment. It is connected with the fact the specific gravity (density) of aluminum is small - amounting to $2.7 \mathrm{~g} / \mathrm{cm}^{3}$, which is equivalent to approximately $30 \%$ of the density of copper, and the fact that it has a higher corrosion resistance. Due to favourable properties of aluminum and its alloys, it is widely used in the automotive, aerospace and building industry $[1,2]$.

The most popular aluminum alloys are silumins i.e. casting alloys in which the major alloying element is Si. The Si addition enhances alloy's castability, improves its hardness and abrasion resistance [3]. Si is characterised by a very low coefficient of thermal expansion $\left(\alpha_{\mathrm{Si}} \approx 3 \times 10^{-6} / \mathrm{K}\right)$ when compared with aluminum $\left(\alpha_{\mathrm{Al}} \approx 22.2 \times 10^{-6} / \mathrm{K}\right)$ and thus it improves dimensional stability of parts made of Al-Si alloys, e.g. engine pistons made of the AlSi20 alloy $[4,5]$. Alloys with a lower Si concentration are used to obtain abrasion-resistant coatings on metal sheets for production of car silencers [6]. The abrasion resistance of alloys is provided by hard $\mathrm{Si}$ crystals placed in the aluminum matrix. As far as plastic properties are concerned, it is important that the size of Si crystals is as small as possible, which is achieved by rapid cooling or chemical modification of alloy [3].

*corresponding author; e-mail: bratek@wip.pcz.pl
In the present work Al-Si alloys were obtained by physical vapor deposition (PVD) magnetron sputtering. This method allows to produce multicomponent alloys with nanocrystalline structure [7]. Al-Si alloys manufactured by this method do not exhibit segregation of components, typical for solidification during the liquid phase, and concentration of the components in the whole volume is homogeneous.

Like in all metals, impurities, alloying additions or defects of the crystal structure cause an increase of $\mathrm{Al}$ resistivity. Resistivity of Al-Si alloys is higher than that of pure aluminum [8]. Furthermore, oxidation of aluminum causes formation of a thin dielectric $\mathrm{Al}_{2} \mathrm{O}_{3}$ film on the $\mathrm{Al}$ surface [9].

The paper presents the results of measurements of resistance of thin coatings made of Al-Si alloys, with a different Si content.

\section{Substance}

$\mathrm{Al}$ and $\mathrm{Si}$ form an eutectic phase equilibrium system. The coatings are prepared from three foundry alloys AlSi7 (hypo-eutectic), AlSi11 (peri-eutectic) and AlSi20 (hypereutectic). The AlSi7 and AlSi20 alloys were used in the as-cast state. The AlSi11 alloy was additionally subjected to homogenisation at $515^{\circ} \mathrm{C}$ for $6 \mathrm{~h}$, cooled in warm water and modified (AlSi11-M) with a TiAlB mortar $(0.1 \mathrm{wt} \% \mathrm{Ti})$. The AlSi20 alloy was used in the state after homogenisation (AlSi20-H) and after modification (AlSi20-M). The alloys were used to obtain targets $(\emptyset 109 \mathrm{~mm})$ which were mounted on magnetrons in the vacuum chamber of a B-90 Hochvakuum Dresden coater. Sputtering was carried out at $0.4 \mathrm{MPa}$ pressure chamber and 14.5-27.5 sccm argon flow. The coatings were deposited at a rate of $55-74 \mathrm{~nm} / \mathrm{min}$ on a substrate of single-crystal silicon $\mathrm{Si}$ (100) and ferritic steel X2CrTi12 sized $10 \times 10 \mathrm{~mm}$. Thickness of the prepared coatings ranged from 9 to $10.8 \mu \mathrm{m}$. 


\section{Methodology}

The structure of the coatings was examined using the scanning microscopy (JEOL JSM 5400) and X-ray diffractometer (Seifert 3003TT). The filtered Co $K_{\alpha}$ radiation $\lambda=0.17902 \mathrm{~nm}$, generated by a voltage $U=30 \mathrm{kV}$ and a current $I=40 \mathrm{~mA}$ was applied. The microscopic study was performed on cross-sections of the coatings deposited on ferritic steel. The diffraction study was performed on the surface of the coatings deposited on silicon substrate, in the range of diffraction angles $20-120^{\circ}$, with step $0.15^{\circ}$ and a counting time of $5 \mathrm{~s} /$ step. Identification of the phase composition of the coatings was made using PDF4+ database.

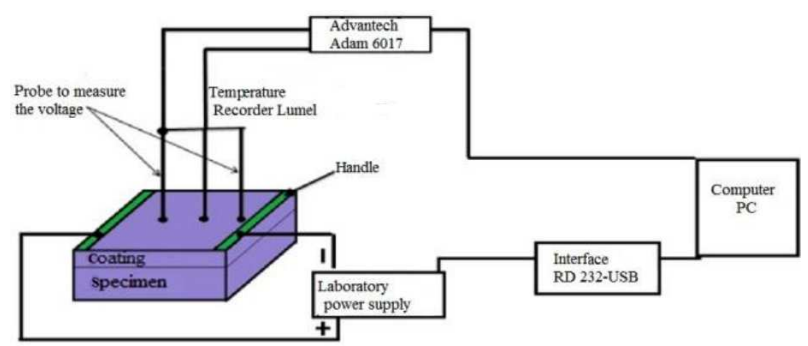

Fig. 1. A block diagram of the position for measuring the resistance of the coatings.

Resistance measurements were carried out by the four-point method [10] using the equipment presented in Fig. 1. The coatings deposited on monocrystalline Si were connected to a direct current circuit by two flat electrodes, which were attached to their surface. The current value was regulated using a Manson SDP 2210 power supply. Voltage drops were recorded by two probes, placed $5 \mathrm{~mm}$ from each other and perpendicular to the electrodes, applied to the central part of the coating. Based on the voltage drops the resistance $R$ was calculated using DESYLab software.

During the resistance tests, the temperature of the coating was measured with a LUMEL resistance meter. Temperature changes were effected by successive changes of voltage and current. In all of the set conditions of voltage, current and temperature, the coatings were annealed for $10 \mathrm{~min}$. The temperature of the coatings was varied between 30 and $75^{\circ} \mathrm{C}$.

\section{Results}

The investigation of the microstructure of the coatings revealed coexistence of two phases. In SEM images of the cross-sections of the coatings, a separation of fine $\mathrm{Si}$ crystallites from the aluminum matrix $\alpha$-Al is visible (Fig. 2). The amount of the formed crystals was the biggest in the coating containing the highest Si addition (20\%). The crystals were elongated in shape and arranged in the direction perpendicular to the surface. Probably, this is a result of preferential formation of new $\mathrm{Si}$ crystals on the crystals formed earlier. The average diameter of a $\mathrm{Si}$ grain in the direction parallel to the substrate was $25 \mu \mathrm{m}$.

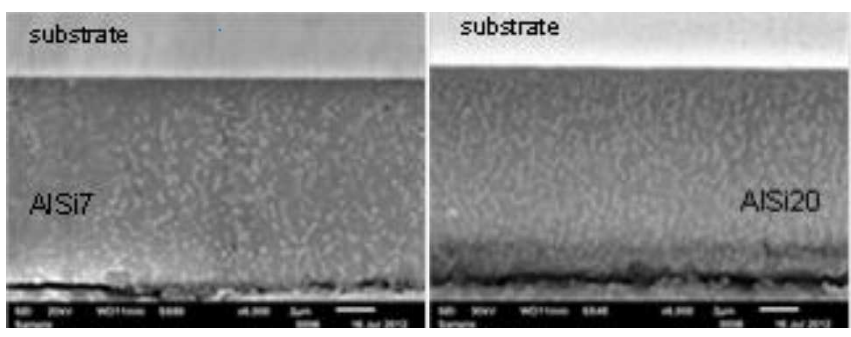

Fig. 2. Cross-section of coating (a) AlSi7 and (b) AlSi20, recorded by SEM.

The X-ray diffraction study confirmed an increase of the volume fraction of Si crystallites in the structure of the coating with an increase of Si content in the chemical composition of alloy (Fig. 3). Diffraction peaks originating from Si were the lowest for the AlSi7 alloy and the highest for AlSi20 alloy. The average size of $\mathrm{Si}$ and $\alpha$-Al crystallites as calculated by the Scherrer formula was 22 $25 \mathrm{~nm}$ (peak $\mathrm{Si}(111)$ ) and 32-38 nm (peak $\alpha$-Al (311)), respectively.

Furthermore, it was revealed that the surface of the samples is covered by a thin film of both $\mathrm{Al}_{2} \mathrm{O}_{3}$ and $\mathrm{SiO}_{2}$.

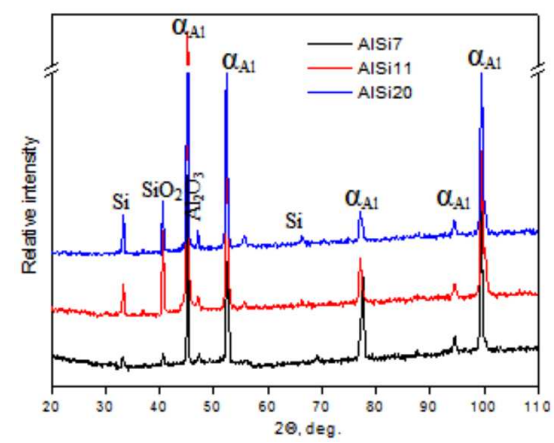

Fig. 3. X-ray diffraction patterns of the coatings.

Current-voltage measurements are shown in Fig. 4. Current dependences of voltage are linear with a similar slope of $0.12-0.14 \mathrm{~V} / \mathrm{A}$. The maximum values of voltage $(0.13 \mathrm{~V})$ and current $(10 \mathrm{~A})$ reached during all measurements were similar for all the coatings. The lowest slope was indicated for the coating with the lowest $\mathrm{Si}$ concentration, being a result of the highest amount of $\mathrm{Al}$ in the alloy, which improves electrical conductivity.

Comparison of current dependences of the voltage curve as well as temperature dependence of the resistance $R(T)$ (Fig. 5) revealed that the highest value of the power was dissipated on the coating produced with the homogenised alloys.

The resistance of the samples was increasing with the temperature increase to $\mathrm{ca} .40^{\circ} \mathrm{C}$ and $50^{\circ} \mathrm{C}$ for the AlSi20 and AlSi11 alloys, respectively. At higher temperatures the resistance reached a mean value of $0.12 \Omega$. The AlSi7 coating revealed the lowest resistance and it reached a maximum temperature of $\approx 55^{\circ} \mathrm{C}$. The highest temperature of $\approx 75^{\circ} \mathrm{C}$ was observed for the AlSi20-H coating. 


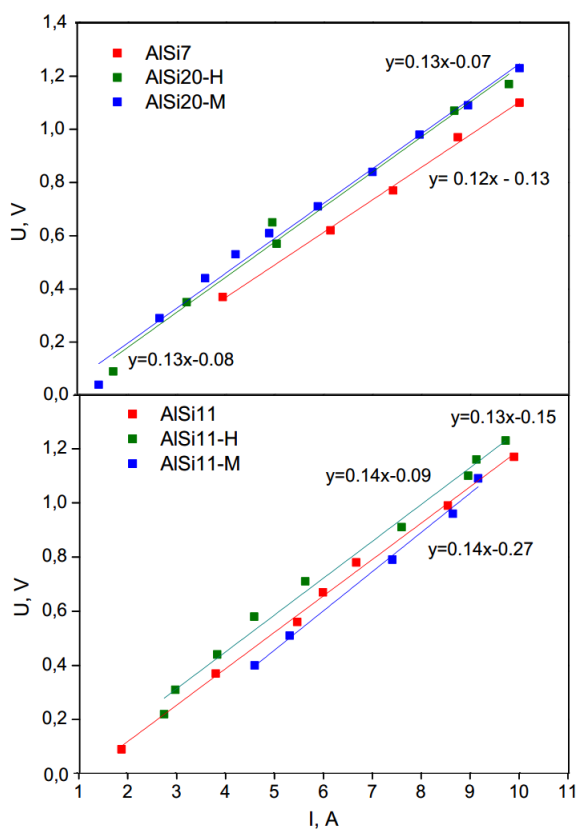

Fig. 4. Current-voltage dependences for the investigated $\mathrm{Al}-\mathrm{Si}$ coatings.

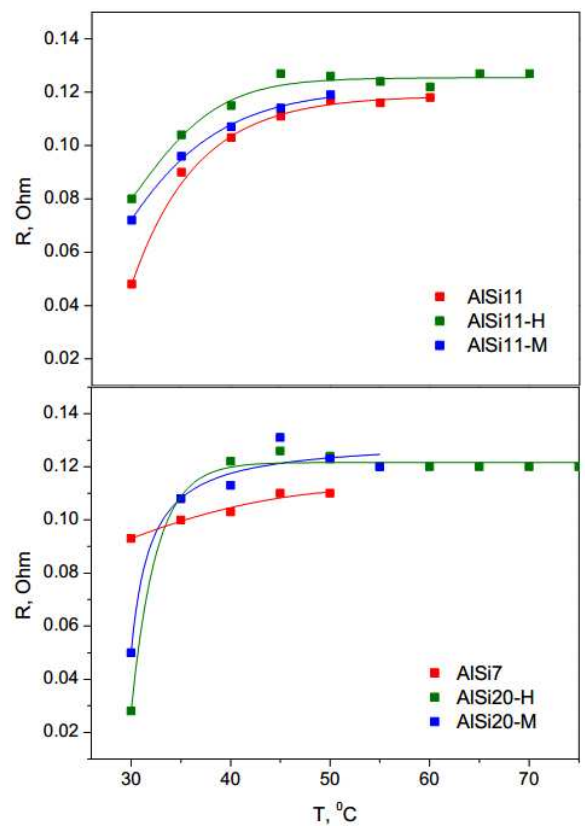

Fig. 5. Temperature dependences of the resistance measured for the investigated coatings.

\section{Conclusions}

The study of the AlSi coatings prepared by PVD revealed an influence of $\mathrm{Si}$ content on the electrical resistance of the coatings. An increase of Si content in the chemical composition of the coatings resulted in an increase of their resistance and the maximum temperature to which the coating heats up. The resistance of the coatings increases with increasing temperature until the determination of the mean level of $0.12 \Omega$, ranging from $\approx 50^{\circ} \mathrm{C}$. On the surface of the AlSi coatings a thin film of aluminum and silicon oxides occurs, and its thickness may increase during resistance heating. The oxides on the surface of the coatings enhance their resistance. Additionally, they have a negative influence on the contact area between the coating and the electrodes, which hampered measurements at initial low voltages.

\section{References}

[1] The Handbook of Electrical Resistivity - New Materials and Pressure Effects, Materials and Devices Series, Vol. 15, Ed. G.T. Dyos, IET, Stevenage 2012.

[2] S. Fassbinder, Conductive Materials, Practical Applications of Conductive Materials, German Copper Institute, Düsseldorf 2010.

[3] Z. Poniewierski, Crystallization, Structure and Properties of Silumins, WNT, Warsaw 1986 (in Polish).

[4] E. Czekaj, Nickel-Free Piston Silumin with Improved Dimensional Stability, Foundry Research Institute, Kraków 2011 (in Polish).

[5] B. Kucharska, A. Wróbel, E. Kulej, Z. Nitkiewicz, Solid State Phenom. 163, 286 (2010).

[6] A. Wróbel, B. Kucharska, Arch. Metall. Mater. 55, 205 (2010).

[7] B. Wendler, Functional Coatings by PVD and CVD Methods, Publishing House of the Institute for Sustainable Technologies - National Research Institute, Radom 2011.

[8] B. Kucharska, M. Spalik, Solid State Phenom. 223, 137 (2015).

[9] B. Kucharska, A. Wróbel, Opt. Appl. 39, 889 (2009).

[10] M. Lisowski, The Measurements of Resistivity and Dielectric Permittivity of Solid Dielectrics, The Publishing House of the Wrocław University of Technology, Wrocław 2004 (in Polish). 